\title{
Ethylene and rooting of mung bean cuttings. The role of auxin induced ethylene synthesis and phase-dependent effects
}

\author{
Geert-Jan De Klerk · Jana Hanecakova
}

Received: 1 June 2006/Accepted: 23 June 2008/Published online: 26 July 2008

(C) The Author(s) 2008

\begin{abstract}
We have re-examined the role of ethylene during rooting of mung bean cuttings. Cuttings were treated for 5 days with a low or a high concentration of NAA (naphthaleneacetic acid). During this 5 days period, we also applied STS (silverthiosulfate, an inhibitor of ethylene action) or ACC (1-aminocyclopropane-1-carboxylic acid, a direct precursor of ethylene). At high NAA concentration, STS promoted and ACC inhibited rooting, respectively. At low NAA concentration, the effects were opposite, STS being inhibitory and ACC promotive. AVG (aminoethoxyvinylglycine, an inhibitor of ethylene synthesis) gave similar results as STS. Together, these data suggest supraoptimal and suboptimal ethylene levels in the tissue at high and low NAA concentration, respectively. We also examined whether the effect of ethylene varied during the successive phases of the rooting process. Thus, we gave $24 \mathrm{~h}$ pulses with either STS or ACC during the rooting treatment. During the first two days $(0-48 \mathrm{~h})$, ACC-pulses were promotive and STS-pulses inhibitory. Later on (48-168 h), the ACC-pulses were
\end{abstract}

G.-J. De Klerk $(\bowtie) \cdot$ J. Hanecakova

Wageningen Tissue Culture Centre, Biodiversity and Breeding, Wageningen University and Research, PO Box 16, 6700 AA Wageningen, The Netherlands e-mail: geertjan.deklerk@wur.nl

J. Hanecakova

Department of Plant Physiology, Comenius University,

Mlynska dolina B2, 84215 Bratislava, Slovakia inhibitory and the STS-pulses promotive. Whether this effect was observed or not was dependent on the NAA concentration. These data indicate that ethylene promotes or inhibits rooting depending on the stage in the rooting process. When ACC was added only during the initial period, rooting was increased at all NAA concentrations in a NAA dose-response curve and the optimal NAA concentration remained the same. This suggests that ethylene renders more cells responsive to NAA.

Keywords ACC - Adventitious root formation . Auxin · Micropropagation - STS · Vigna radiata

\section{Abbreviations \\ ACC 1-Aminocyclo-propane-1-carboxylic acid AVG Aminoethoxyvinylglycine \\ NAA 1-Naphthaleneacetic acid \\ STS Silverthiosulfate}

\section{Introduction}

Cuttings prepared from mung bean seedlings have been used as a model to examine adventitious root formation and in bioassays to identify putative rooting-promoting substances (Arthur et al. 2004; De Klerk 1999; Kollarova et al. 2005; Mutui et al. 2005; Ricci et al. 2005). Major advantages of mung bean cuttings concern their convenience: seeds are available in large numbers, cuttings can be prepared 
ca. 7 days after sowing by excision of the roots, and the number of adventitious roots can be scored 10 days after the start of the rooting treatment.

Ethylene has been implicated in adventitious root formation but its role is unclear. With mung bean cuttings, researchers have obtained contradictory results: it has been reported that in mung bean ethylene promotes, inhibits, or does not influence rooting (see Mudge 1988). Contradictory results have also been obtained in, e.g., tomato (see Clark et al. 1999). In studies on the role of ethylene during rooting, various pitfalls should be considered (cf. De Klerk et al. 1999). First, cuttings may themselves produce large amounts of ethylene in response to the auxin treatment (for mung bean cuttings: Geneve and Heuser 1982). In mung bean it has also been found that genes involved in ethylene synthesis, are upregulated by auxin (Song et al. 2005). Second, in the portion of the stem from where the roots regenerate, ethylene may be trapped when this portion is immersed: because gases do not diffuse easily through water, ethylene may accumulate to high levels in immersed tissues (Jackson 1985). Third, the effect of ethylene is stage-specific and depends on the phase of the rooting treatment (De Klerk et al. 1999).

In the present article, we examine the role of ethylene in mung bean, focusing on the effect of ethylene synthesis brought about by auxin, and on the putative differential effect of ethylene during the successive phases of root formation. Because an adequate measurement of ethylene in the tissue from where the roots regenerate is difficult (see Discussion), the role of enhancement of ethylene synthesis by auxin has been evaluated using STS (an ethylene inhibitor) and ACC (a direct precursor of ethylene).

\section{Materials and methods}

Plant material

Mung bean seeds were purchased from Zaadhandel Van Der Wal, Hoogeveen, The Netherlands. Two batches of seeds were used. We noticed differences among these batches, e.g., with respect to the optimal NAA concentration. The seeds were surface-sterilized in $1 \%(\mathrm{w} / \mathrm{v}) \mathrm{NaOC} 1$, rinsed three times in sterile water and sown in culture tubes $(2.2 \mathrm{~cm}$ diameter, $15 \mathrm{~cm}$ high) with $5 \mathrm{ml}$ medium (one seed per tube).
The medium was composed of MS macro- and microelements (Murashige and Skoog 1962) and $6 \mathrm{~g}^{-1}$ agar (brand: Becton and Dickinson). After 79 days of germination at $25^{\circ} \mathrm{C}$ at a light intensity of $30 \mu \mathrm{E} \mathrm{m}^{-2} \mathrm{~s}^{-1}$ (Philips TL 33) for $16 \mathrm{~h}$ per day, cuttings were prepared by excising the primary root. Each cutting consisted of a 3-cm long hypocotyl, the cotyledons, the epicotyl, two primary leaves and the unexpanded apical bud.

\section{Rooting conditions}

The cuttings were cultured in tubes $(2.2 \mathrm{~cm}$ diameter, $15 \mathrm{~cm}$ high) with $5 \mathrm{ml}$ semi-solid medium and with a loose lid so that gases could escape easily. The medium was the same as the rooting medium used for apple microcuttings (De Klerk et al. 1995). NAA was added before autoclaving, and filter-sterilized ACC, AVG and STS after autoclaving. The cuttings were stuck in the medium for $2 \mathrm{~cm}$. The cultures were kept at $25^{\circ} \mathrm{C}$ in the dark for five days. Then, the cuttings were transferred to the same medium but without plant growth regulators and to the light (16-h photoperiod; $35 \mu \mathrm{mol} \mathrm{m} \mathrm{s}^{-1}$ ). An exception is the experiment shown in Fig. 4. In this experiment, the cuttings were transferred to hormone-free medium and to the light after 7 days $(168 \mathrm{~h})$. When the plant growth regulators were added as a pulse, the cuttings were transferred for the period of the pulse to medium with $100 \mu \mathrm{M}$ STS (Fig. 4) or $300 \mu \mathrm{M}$ ACC (Figs. 5 and 6) and after that transferred back to the previous medium. During the pulses, NAA was present in the medium at the proper concentration. The roots regenerated from the lower $1 \mathrm{~cm}$ of the cutting. In the pulse-experiment shown in Fig. 6, the cuttings were cultured during the first day $(0-24 \mathrm{~h})$ in the dark on medium with or without $300 \mu \mathrm{M}$ ACC and with increasing concentrations of NAA, during the following $4 \mathrm{~d}(24-120 \mathrm{~h})$ on medium with the same concentrations of NAA (but without ACC), and after that transferred to the light and to hormone-free medium. Roots were counted after 11 or 12 days under a dissecting microscope.

\section{Statistics}

For each treatment, 30 cuttings were used. The means are given \pm SE. Significance of differences was evaluated in a Student $t$-test. 


\section{Results}

Interactive effects of NAA, STS and ACC

Mung bean cuttings were cultured for 5 days with increasing concentrations of NAA in absence or presence of $10 \mu \mathrm{M}$ STS and then transferred to medium without plant growth regulators. At low NAA concentrations ( 0 and $10 \mu \mathrm{M}), 10 \mu \mathrm{M}$ STS had no effect, but at high NAA concentrations, in particular at $100 \mu \mathrm{M}$ NAA, $10 \mu \mathrm{M}$ STS promoted rooting (Fig. 1).

Cuttings were also treated with a range of STS concentrations at the optimal $(30 \mu \mathrm{M})$ and at a supraoptimal NAA concentration $(100 \mu \mathrm{M})$. The effect of an increase of NAA from 30 to $100 \mu \mathrm{M}$ depended on the STS concentration. At low or high STS-levels, the increase of NAA resulted in less or more roots, respectively (Fig. 2). There was no toxic effect of STS: even at the highest concentration, $100 \mu \mathrm{M}$, the cuttings looked normal and only displayed reduced root formation. It should be remembered that the cuttings were cultured with STS for only 5 days. A similar experiment, but with only few, selected concentrations, was done with the ethylene-synthesis inhibitor AVG. We obtained essentially the same results.

Cuttings were also treated with a range of ACC concentrations at a high $(10 \mu \mathrm{M})$ and at a low $(3 \mu \mathrm{M})$ NAA concentration. The increase of NAA resulted in

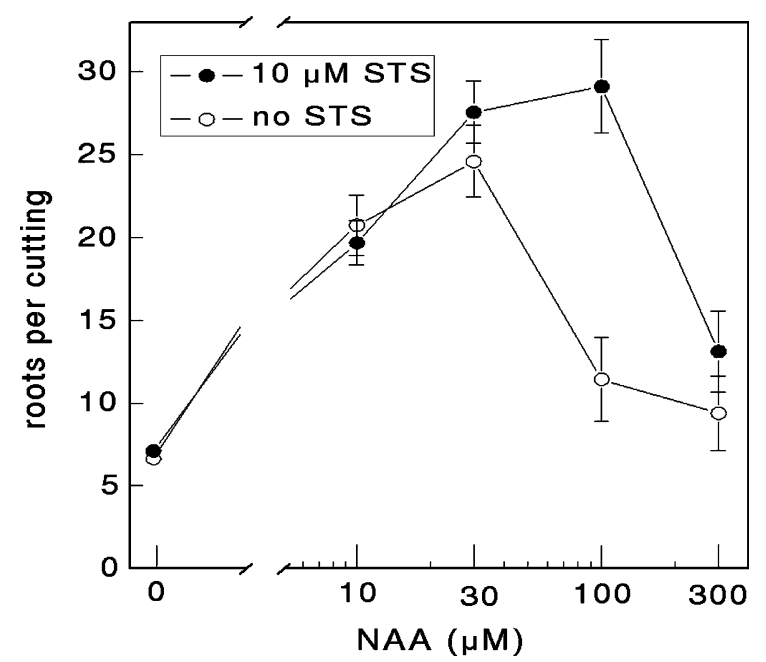

Fig. 1 Effect of increasing concentrations of NAA on rooting of mung bean cuttings with and without $10 \mu \mathrm{M}$ STS more roots or less roots at low or high ACC-levels, respectively. Generally, opposite shifts of the doseresponse curves at high and low NAA concentration were observed for ACC and STS: The dose-response curves of ACC with $10 \mu \mathrm{M}$ NAA had shifted to the left as compared to the dose-response curve with $3 \mu \mathrm{M}$ NAA (Fig. 3). The dose-response curves of STS with $100 \mu \mathrm{M}$ NAA had shifted to the right as

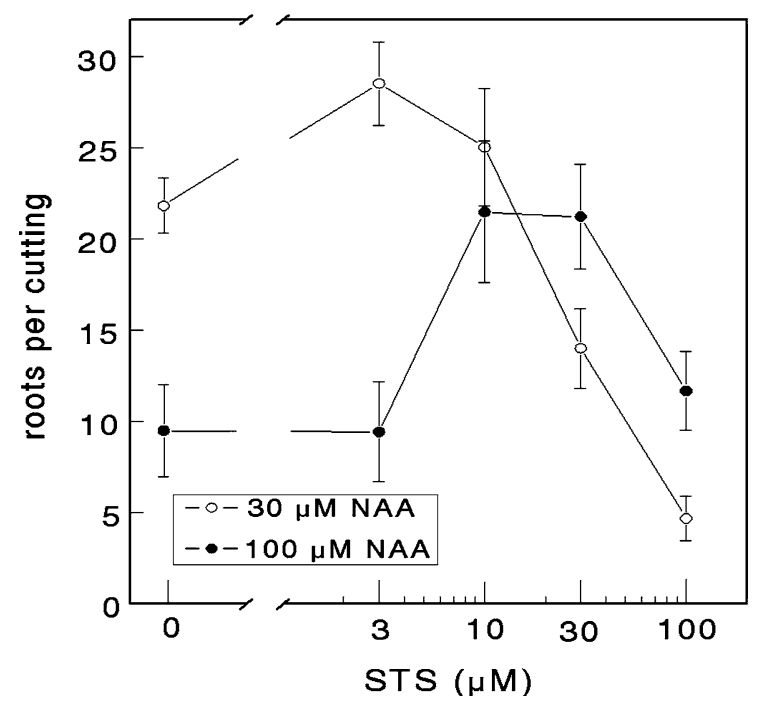

Fig. 2 Effect of increasing concentrations of STS on rooting of mung bean cuttings in the presence of $30 \mu \mathrm{M}$ NAA (optimal concentration) or $100 \mu \mathrm{M}$ NAA (supraoptimal concentration)

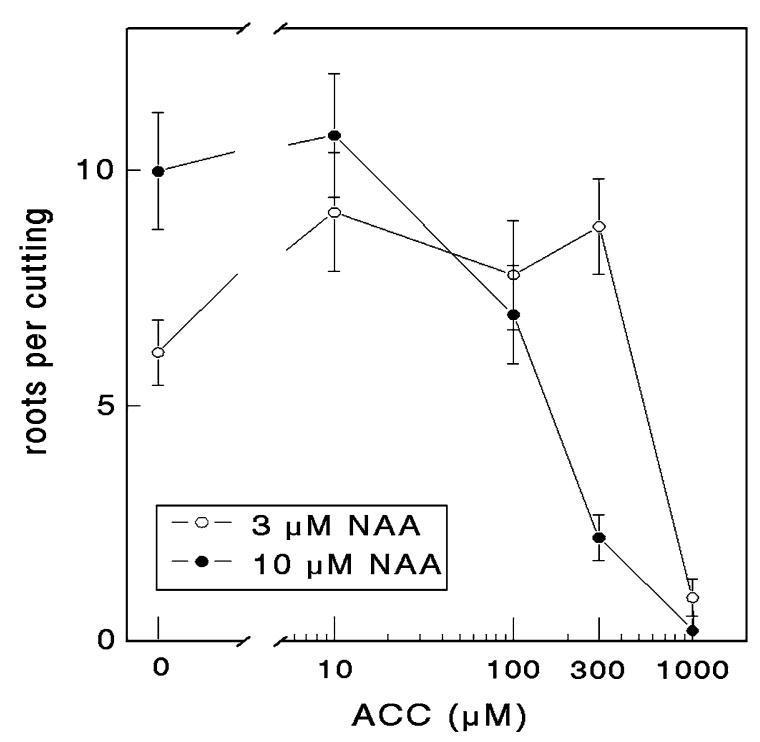

Fig. 3 Effect of increasing concentrations of ACC on rooting of mung bean cuttings in the presence of $3 \mu \mathrm{M}$ NAA (low suboptimal concentration) or $10 \mu \mathrm{M}$ NAA (suboptimal concentration) 
compared to the dose-response curve with $30 \mu \mathrm{M}$ NAA (Fig. 2).

\section{Stage-dependent effect of ethylene}

In apple microcuttings, we previously found a strong stage-dependent effect of ethylene by giving $24 \mathrm{~h}$ pulses with either STS or ACC (De Klerk et al. 1999). Similar experiments were carried out in mung bean. At $30 \mu \mathrm{M}$ NAA (Fig. 4a), $24 \mathrm{~h}$ STS-pulses were inhibitory when administered at the beginning of the rooting treatment (from 0 to $48 \mathrm{~h}$ ). Later on (96-120 h), STS-pulses were slightly promotive. At the supraoptimal auxin concentration $(100 \mu \mathrm{M}$ NAA, Fig. 4b), STS-pulses had no effect up to $48 \mathrm{~h}$. After that, STS-pulses were strongly promotive up to $144 \mathrm{~h}$. Together, these data indicate that ethylene is promotive in the first days of the rooting treatment, but inhibitory after that.

From pulses with ACC we reached a similar conclusion about the stage-dependent effect of ethylene: ACC was stimulatory just after taking the
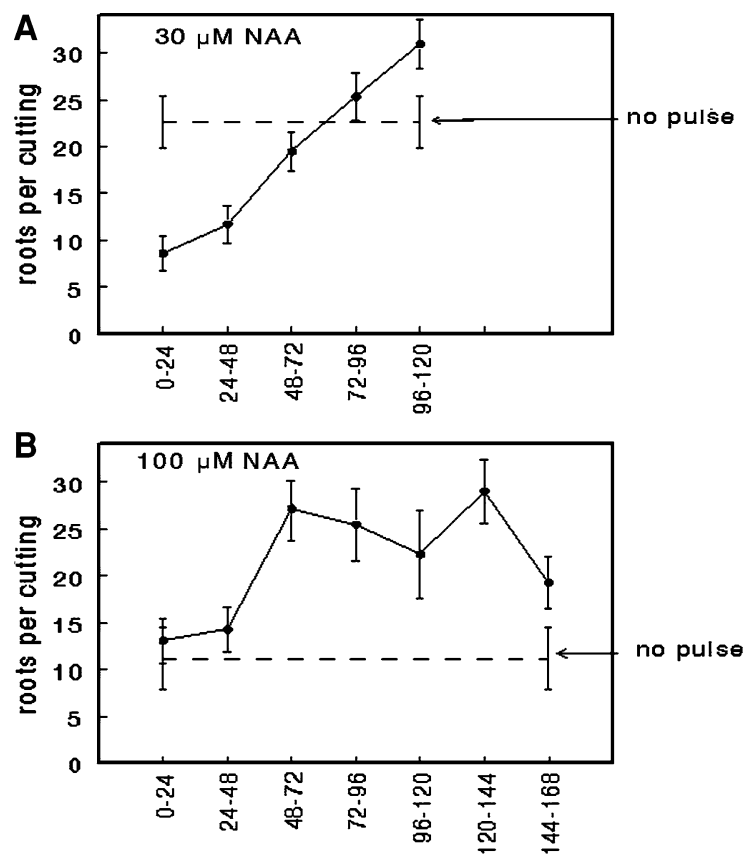

timing of pulse with $100 \mu \mathrm{M}$ STS (h)

Fig. 4 Effect of 24-h pulses with $100 \mu \mathrm{M}$ STS on rooting of mung bean cuttings. Rooting was carried out at $30 \mu \mathrm{M}$ NAA (optimal concentration) (a) or at $100 \mu \mathrm{M}$ NAA (supraoptimal concentration) (b). During the STS pulse, NAA was also present cutting in particular at the low auxin concentration (Fig. 5a). Later on (72-120 h), ACC was inhibitory at the high auxin concentration (Fig. 5b). It should be noted that in this experiment, $100 \mu \mathrm{M}$ NAA induced a higher number of roots than $30 \mu \mathrm{M}$ NAA, the concentration that was optimal in the other experiments.

We were interested how ethylene promoted rooting during the initial phase. Therefore, we gave a 24$\mathrm{h}$ pulse with ACC during the initial day just after taking the cutting. Both during the pulse and in the four days after the pulse a range of NAA concentrations was applied. Figure 6 shows that the ACC treatment stimulated rooting at all auxin concentrations. The dose-response curve of NAA did not shift to left or right by the one-day ACC treatment. In this
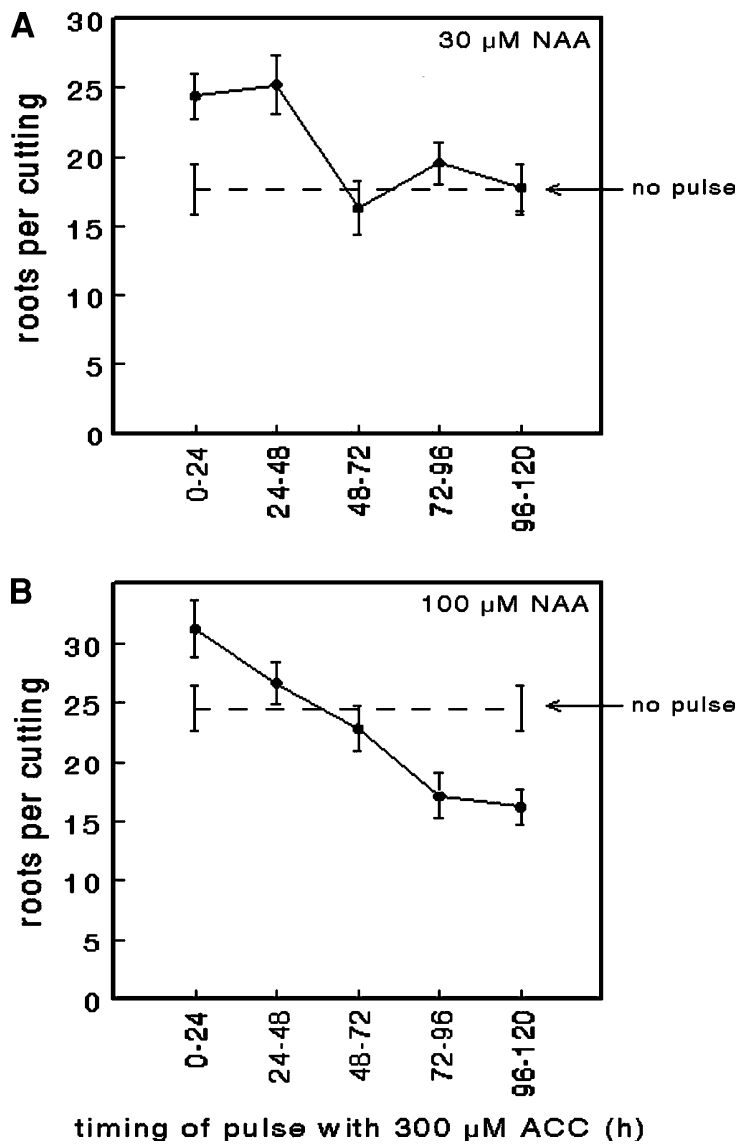

Fig. 5 Effect of 24-h pulses with $300 \mu \mathrm{M}$ ACC on rooting of mung bean cuttings. Rooting was carried out at $30 \mu \mathrm{M}$ NAA (optimal concentration) (a) or at $100 \mu \mathrm{M}$ NAA (supraoptimal concentration) (b). During the ACC pulse, NAA was also present 


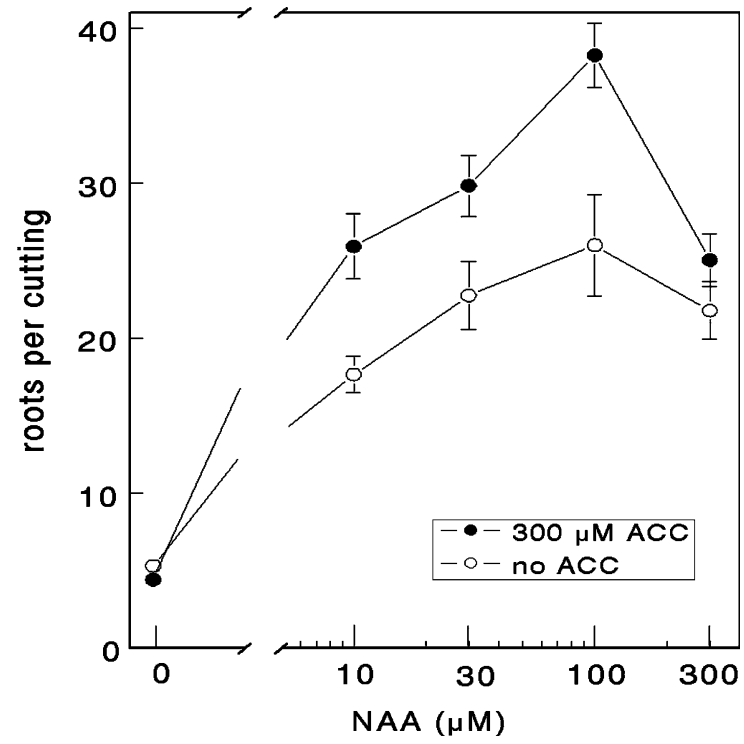

Fig. 6 Effect of a pretreatment with ACC on rooting of mung bean cuttings. The cuttings had been cultured during the first day $(0-24 \mathrm{~h})$ with and without $300 \mu \mathrm{M}$ ACC and after that for 4 days $(24-120 \mathrm{~h})$ on medium with increasing NAA concentrations

experiment, the same batch of seeds was used as in the experiment shown in Fig. 5. Note that $100 \mu \mathrm{M}$ NAA resulted in the highest number of roots (compare with Figs. 1 and 5).

\section{Discussion}

The effects of applied ACC and STS depend on the auxin concentration

It is well known that auxin promotes ethylene formation. This has also been reported for mung bean cuttings (Geneve and Heuser 1982; Song et al. 2005). We have measured ethylene levels in the head space of taped culture containers and found a strong increase of ethylene when NAA had been added to the medium (data not shown). However, the ethylene level should be measured in the tissue from where the roots regenerate, viz., in the part of the stem that is immersed in the medium. In this portion of the cutting, the ethylene level is expectedly much higher because the auxin concentration in the lower part of the shoot is higher (e.g., De Klerk et al. 1990) and because ethylene cannot easily escape from immersed tissues (cf. Voesenek et al. 1993).
Actually, the situation is more complicated, since oxidation of ACC (a precursor of ethylene that is rapidly converted to ethylene in plant tissues by ACC-oxidase) to ethylene is also reduced by the partial anaerobic conditions in the immersed portion of the cutting (cf. Voesenek et al. 1993). Measurements of ethylene in the relevant portion of the cutting are feasible but complicated and were therefore not performed. Nevertheless, a critical study on endogenous ethylene levels in the shoot is necessary to further substantiate the conclusions of this paper.

The effect of added NAA on ethylene production in mung bean is shown in this paper by the opposite effect of an increase of NAA at high and low levels of STS (an inhibitor of ethylene action, Fig. 2) and ACC (the direct precursor of ethylene in the biosynthetic pathway, Fig. 3). At low STS- and high ACC-levels, an increase of NAA resulted in reduced rooting. In agreement with this, at high STS and low ACC-levels an increase of NAA resulted in enhanced rooting. This indicates that at high NAA concentrations, ethylene synthesis in the cuttings was high and that ethylene became inhibitory; at low NAA concentration, the level of endogenous ethylene was suboptimal. In Fig. 1, dose-response curves of NAA are shown with and without $10 \mu \mathrm{M}$ STS. Ten $\mu \mathrm{M}$ STS promoted rooting only at high NAA concentrations, in particular at $100 \mu \mathrm{M}$ NAA (Fig. 2). This again indicates that ethylene endogenously produced at $100 \mu \mathrm{M}$ NAA, inhibited rooting. Results with inhibitors like STS should be treated with care because of possible, unexpected side-effects. In this study, the effect of STS is most likely related to inhibition of ethylene action because AVG, an inhibitor of ethylene synthesis, had similar results and because addition of ACC, a compound that is readily metabolized to ethylene, gave just opposite results.

Stage dependent effect of ethylene

Just as other regeneration processes (Christianson and Warnick 1983; De Klerk et al. 1995; De Klerk 1999), adventitious root formation can be dissected into three phases. First, certain cells develop competence to respond to the rhizogenic signal (auxin). This is denoted as dedifferentiation phase. In the next phase, the induction phase, these cells become determined to form roots by the rhizogenic action of auxin. After 
that, morphological differentiation occurs during which the roots develop. During this third phase auxin is inhibitory. Previously (De Klerk et al. 1999), we have shown in apple microcuttings that ethylene is promotive during the first phase, but inhibitory during the second. The present data indicate the same phase-dependent effect of ethylene in mung bean cuttings: ethylene is at first promotive (as shown by the promotion of rooting by ACC-pulses and the inhibition by STS-pulses) and after that inhibitory (ACC-pulses inhibit and STS-pulses promote rooting). When ACC or STS are present for the full treatment, the resulting effect of the opposite actions in the subsequent phases depends among others on how much of the compound (ACC or STS) is still left in the medium.

The mechanism how ethylene enhances rooting during the initial phase has been elucidated to some extent. Application of ACC during the initial day only increased rooting at all NAA concentrations in a dose-response curve of NAA. Thus, more cells in the cutting had become capable to respond to the rhizogenic action of auxin. In flooded plants, ethylene accumulation increases sensitivity to auxin and results in adventitious root formation (Visser et al. 1996). In transgenic plants that have been rendered insensitive towards ethylene, rooting is reduced (Clark et al. 1999; McDonald and Visser 2003).

During the induction phase (second phase) of rooting in apple, the root meristemoid is being formed. This involves the establishment of polarity. Polar auxin transport might play a major role in the establishment of the polarity. Because ethylene blocks polar auxin transport (Suttle 1988), it might be that it inhibits during the induction phase by interfering with the establishment of polarity. Indeed, another compound that interferes with the polar auxin transport, triiodobenzoic acid (TIBA), also blocks rooting in the same period (G. J. de Klerk unpublished results). Inhibition of organized growth by ethylene has been reported before (Wochok and Wetherel 1971).

\section{Conclusions}

Papers on the effect of ethylene on rooting have reported contradictory results. The present paper shows that the relationship between ethylene and rooting is multifaceted. (1) Ethylene has opposite effects in the successive phases of rooting, being promotive during the initial stage and inhibitory after that. (2) The direction of the effect of added ethylene or ethylene inhibitors depends on the endogenous content that in turn depends on auxin concentration in the medium and on the extent of immersion. (3) It should also be considered, that ethylene readily escapes from tissues as it is a gaseous compound, but that escape from immersed tissues is much reduced.

Open Access This article is distributed under the terms of the Creative Commons Attribution Noncommercial License which permits any noncommercial use, distribution, and reproduction in any medium, provided the original author(s) and source are credited.

\section{References}

Arthur GD, Stirk WA, Van Staden J (2004) Screening of aqueous extracts from gelling agents (Agar and Gelrite) for root-stimulating activity. S Afr J Bot 70:595-601

Christianson ML, Warnick DA (1983) Competence and determination in the process of in vitro shoot organogenesis. Dev Biol 95:288-293. doi:10.1016/0012-1606 (83)90029-5

Clark DG, Gubrium EK, Barrett JE, Nell TA, Klee HJ (1999) Root formation in ethylene-insensitive plants. Plant Physiol 121:53-60. doi:10.1104/pp.121.1.53

De Klerk GJ (1999) Adventitious organogenesis. In: The encyclopedia of cell technology, vol 1. Wiley, New York, pp 12-24

De Klerk GJ, Keppel M, Ter Brugge J, Meekes H (1995) Timing of the phases in adventitious root formation in apple microcuttings. J Exp Bot 46:965-972. doi:10.1093/ jxb/46.8.965

De Klerk GJ, Ter Brugge J, Smulders R, Benschop M (1990) Basic peroxidases and rooting in microcuttings of Malus. Acta Hortic 280:29-36

De Klerk GJ, Van Der Krieken W, De Jong JC (1999) The formation of adventitious roots: new concepts, new possibilities. In Vitro Cell Dev Biol Plant 35:189-199. doi: 10.1007/s11627-999-0076-Z

Geneve RL, Heuser CW (1982) the effect of IAA, IBA, NAA, and 2,4-D on root promotion and ethylene evolution in Vigna-radiata cuttings. J Am Soc Hortic Sci 107:202-205

Jackson MB (1985) Ethylene and responses of plants to soil waterlogging and submergence. Annu Rev Plant Physiol Plant Mol Biol 36:145-174. doi:10.1146/annurev.arplant. 36.1.145

Kollarova K, Henselova M, Liskova D (2005) Effect of auxins and plant oligosaccharides on root formation and elongation growth of mung bean hypocotyls. Plant Growth Regul 46:1-9. doi:10.1007/s10725-005-5185-z

McDonald MP, Visser EJW (2003) A study of the interaction between auxin and ethylene in wild type and transgenic 
ethylene-insensitive tobacco during adventitious root formation induced by stagnant root zone conditions. Plant Biol 5:550-556. doi:10.1055/s-2003-44790

Mudge KW (1988) Effect of ethylene on rooting. In: Davis TD, Haissig BE, Sankhla N (eds) Adventitious root formation by cuttings. Dioscorides Press, Portland, pp 50-161

Murashige T, Skoog F (1962) A revised medium for rapid growth and bioassays with tobacco tissue cultures. Physiol Plant 15:473-497

Mutui TM, Mibus H, Serek M (2005) Effects of thidiazuron, ethylene, abscisic acid and dark storage on leaf yellowing and rooting of Pelargonium cuttings. J Hortic Sci Biotechnol 80:543-550

Ricci A, Carra A, Rolli E, Bertoletti C, Branca C (2005) The weak cytokinins N,N-bis-(1-naphthyl)urea and N,N'-bis(2-naphthyl)urea may enhance rooting in apple and mung bean. Plant Cell Tissue Organ Cult 83:179-186. doi: 10.1007/s11240-005-4931-2

Song JD, Kim JH, Lee DH, Rhew TH, Cho SH, Lee CH (2005) Developmental regulation of the expression of 1-aminocyclopropane-1-carboxylic acid (ACC) synthase and ACC oxidase genes in hypocotyls of etiolated mung bean seedlings. Plant Sci 168:1149-1155. doi:10.1016/j.plantsci. 2004.11.015

Suttle JC (1988) Effect of ethylene treatment on polar IAA transport, net IAA uptake and specific binding of n-1naphthylphthalamic acid in tissues and microsomes isolated from etiolated pea epicotyls. Plant Physiol 88: 795-799

Visser EJW, Cohen JD, Barendse GWM, Blom CWPM, Voesenek LACJ (1996) An ethylene-mediated increase in sensitivity to auxin induces adventitious root formation in flooded Rumex palustris Sm. Plant Physiol 112: $1687-1692$

Voesenek LACJ, Banga M, Thier RH, Mudde CM, Harren FJM, Barendse GWM et al (1993) Submergence-induced ethylene synthesis, entrapment, and growth in two plant species with contrasting flooding resistances. Plant Physiol 103:783-791

Wochok ZS, Wetherel DF (1971) Suppression of organized growth in cultured wild carrot tissue by 2-chloroethylphosphonic acid. Plant Cell Physiol 12:771-774 